\title{
Transforaminal Epidural Steroid Injection in the Treatment of Pain in Foraminal and Paramedian Lumbar Disc Herniations
}

\author{
Bulent GUCLU1', Levent DENIZ², Yucel YUCE³ ${ }^{3}$ Utku ADILAY4, Hamit AYTAR5, Meryem TURKOGLU, \\ Mehmet TIRYAKI ${ }^{1}$, Recep OZDEK ${ }^{4}$, Burak Orhan BORAN ${ }^{1}$ \\ ${ }^{1}$ Kartal Dr. Lutfi Kirdar Training and Research Hospital, Department of Neurosurgery, Istanbul, Turkey \\ ${ }^{2}$ Marmara Pain Management Center, Bakirkoy, Istanbul, Turkey \\ ${ }^{3}$ Kartal Dr. Lutfi Kirdar Training and Research Hospital, Department of Anaesthesiology and Reanimation, Istanbul, Turkey \\ ${ }^{4}$ Balikesir University School of Medicine, Department of Neurosurgery, Balikesir, Turkey \\ ${ }^{5}$ Neurosurgery Clinic, Aile Hospital, Bahcelievler, Istanbul, Turkey \\ ${ }^{6}$ Mehmet Akif Ersoy Thoracic and Cardiovascular Surgery Training and Research Hospital, Director of Nursing, Istanbul, Turkey
}

Corresponding author: Utku ADILAY utkuadilay@hotmail.com

\section{ABSTRACT}

AIM: To compare the effect of fluoroscopically guided transforaminal epidural steroid injections on radicular pain in foraminal and paramedian lumbar disc herniations.

MATERIAL and METHODS: This study included patients who did not benefit from previous medical treatments or are not suitable for surgery. Transforaminal epidural steroid injections for the treatment of foraminal and paramedian lumbar disc herniation were performed in 370 and 1262 patients, respectively. Every group's preprocedural visual analogue scale (VAS) and 12-week postprocedural VAS scores were recorded, and statistical analysis was performed. The complications noted were also recorded.

RESULTS: The preprocedural and postprocedural mean VAS scores for radicular pain in foraminal disc herniation were $67.11 \pm 4.28$ and $34.78 \pm 3.64$, respectively. However, the preprocedural and postprocedural mean VAS scores in paramedian disc herniation were $62.16 \pm 6.65$ and $19.07 \pm 4.50$, respectively. Statistical analysis of the varying preprocedural and postprocedural VAS scores showed that transforaminal epidural steroid injections were more effective for paramedian disc herniation than for foraminal disc herniation $(p<0.05)$.

CONCLUSION: Transforaminal epidural steroid injections were more effective for paramedian lumbar disc herniation than for foraminal disc herniation, 12 weeks after the procedure.

KEYWORDS: Disc herniation, Foraminal, Lumbar, Paramedian, Transforaminal, Epidural steroid injection

\section{INTRODUCTION}

$\mathrm{R}$ adicular pain is most commonly caused by mechanical compression of the nerve root due to lumbar disc herniation (9). It may spontaneously subside or can be relieved with conservative management. In lumbar disc herniation cases with chronic severe pain or neurological deficit, surgery is indicated. But in patients who do not want to undergo surgery due to unbearable pain, lumbar transforaminal epidural steroid injections can be the treatment of choice.

Other studies showed that in many herniated lumbar disc patients, the clinical features include inflammation caused by biochemical factors alone or with mechanical deformation of lumbar tissues, rather than mechanical factors only $(18,21)$. This indicates the use of corticosteroids to inhibit inflammation and alleviate pain. High concentrations of
Bulent GUCLU (10) : 0000-0002-0012-5706

Levent DENIZ (1) : 0000-0002-8648-1372

Yucel YUCE (D): 0000-0003-0396-1248
UtkU ADILAY (10): 0000-0003-4867-244X

Hamit AYTAR (1D): 0000-0002-4323-542X

Meryem TURKOGLU (1) : 0000-0002-7464-5982 $\begin{array}{ll}\text { Mehmet TIRYAKI } & \text { (D) : 0000-0002-2864-0515 } \\ \text { Recep OZDEK } & \text { (D) : 0000-0002-7625-2269 } \\ \text { Burak Orhan BORAN } & \text { (D) : 0000-0002-1039-888X }\end{array}$ 
corticosteroids and other therapeutic agents are delivered through fluoroscopically guided transforaminal epidural steroid injection (5), and transforaminal epidural steroid injections performed appropriately are clinically effective in treating lumbar and radicular pain $(1,10,23)$. Steroid injection causes neural blockade that alters or interrupts nociceptive input, reflex mechanism of the afferent fibres, self-sustaining activity of neurons and pattern of central neuronal activities $(7,15,20)$. Corticosteroids inhibit the synthesis or release of a number of pro-inflammatory mediators and cause a reversible local anaesthetic effect, reducing inflammation $(7,22)$. The therapeutic effects of epidural steroids are a combination of the primary physiological changes resulting from the procedure and the secondary results from the enhanced pain control that allow integration of other therapeutic modalities. According to studies, the predominant benefit of epidural steroids is its anti-inflammatory effect, although their neurolytic effect on unmyelinated $\mathrm{C}$-fibres has also been demonstrated $(6,11,12)$.

Transforaminal epidural injections result in significantly lesser pain scores in lumbar radiculopathy patients compared with pain scores of patients receiving no treatment, conservative management without injection therapy and lumbar interlaminar epidural injections (19). Transforaminal epidural steroid injections appear to be cost-effective than surgical interventions. This study compared the outcomes of fluoroscopically guided transforaminal epidural steroid injections between foraminal and paramedian lumbar disc herniation in the treatment of radicular pain since it has not yet been studied.

\section{MATERIAL and METHODS}

\section{Patients}

A total of 1748 patients with radicular pain due to foraminal or paramedian lumbar disc herniation who did not benefit from previous medical treatments/physical therapy and who did not want surgical intervention were included in this study. These patients were treated with transforaminal epidural steroid injections based on radicular pain, magnetic resonance imaging (MRI) confirmation of significant foraminal or paramedian lumbar disc herniation and failure of conservative therapy (medical treatments / physical therapy) after an adequate trial. Among the patients, 1632 were reexamined 12 weeks after the procedure and 116 were not able to continue with the study for various reasons. Preprocedural and postprocedural VAS scores and complications were recorded.

The inclusion criteria in this study were radicular pain, MRI confirmation of foraminal or paramedian lumbar disc herniation (Figure 1A-D), failure of conservative therapy (medical treatments / physical therapy) after an adequate trial and at least one site of transforaminal epidural steroid injection. On the other hand, the exclusion criteria included previous spinal surgery at the same level; isthmic or degenerative spondylolisthesis; midsagittal spinal canal diameter $<8$ $\mathrm{mm}$; spinal instability evidenced by the presence of sagittal vertebral translation $>3 \mathrm{~mm}$ and angulation $>10^{\circ}$ on dynamic radiography; cauda equina syndrome; lumbar disc herniation in >1 level; and metabolic diseases such as diabetes mellitus because of the known effects of steroids.

\section{MRI Data Analyses}

All lumbar magnetic resonance images were acquired using a 1.5 Tesla scanner. Images that were obtained at the level of the nerve root engagement correlated with radicular pain. All clinical information was not made known to the wellexperienced radiologist who analysed the preprocedural magnetic resonance images and the existence of foraminal or paramedian lumbar disc herniation. Postprocedural MRI was not done for every patient. Foraminal disc herniation originates from a disc rupture in the extracanalicular portion of the medullary canal (within borders of the pedicles) and compresses the longitudinal emerging root. Paramedian disc herniation presses the spinal cord unilaterally, deforming it into a comma shape.

\section{Procedure}

With the patients in prone position, the procedure was performed using aseptic technique; 1\% lidocaine was diffused into the insertion site through a 22-gauge Quincke spinal needle (Tae-Chang Industrial Co., Korea) inserted using a preganglionic approach to fluoroscopically guided transforaminal epidural steroid injection. In preparing the solution, a syringe with a filter needle (Donghwa C\&M, Korea) was used as dexamethasone was stored in glass ampules. Approximately $1 \mathrm{~mL}$ of contrast media (Pamiray, Dongkook Lifescience, Korea) was used to confirm epidural spread, and $3 \mathrm{~mL}$ of $0.33 \%$ lidocaine (Lidocaine $\mathrm{HCl}$, Huons, Korea) with $4 \mathrm{mg}$ dexamethasone (dexamethasone disodium phosphate, Yuhan, Korea) was injected (Figure 2A, B).

All the patients were reexamined 12 weeks after the procedure. Preprocedural and postprocedural VAS scores (24) for radicular pain and neurologic examination findings along with any complications were recorded, and the 12-week postprocedural VAS scores were obtained to measure the final effect of steroids on VAS scores.

\section{VAS Score Assessment}

The individual patient's preprocedural and postprocedural average VAS scores were calculated, and three different measures of radicular pain were obtained using a horizontal VAS, with $0 \mathrm{~mm}$ indicating no pain and $100 \mathrm{~mm}$ the worst imaginable pain: self-rated radicular pain (thigh and more distal) at present and minimum and maximum self-rated radicular pains during the last 3 days. With these three measures, the mean VAS score for radicular pain was calculated.

This study was performed retrospectively and conducted in accordance with the Declaration of Helsinki (1964). The procedure was performed following patients' understanding and consent, with each patient receiving oral and written information regarding the lumbar disc herniation treatment with transforaminal epidural steroid injections and signing a written informed consent. Moreover, the patients were informed about the study during the clinical study design. The chief complaint of patients was leg pain and low-back pain, and the mean duration of radicular pain before surgery was 
Guclu B. et al: Transforaminal Injection for Lumbar Disc Herniation

5 months \pm 0.4 months. Nonsteroidal anti-inflammatory or analgesic drugs were given prior to injections.

\section{Statistical Method}

The paired sample t-test was performed for the VAS measurements, and the SPSS (21.0) software was used.
The $p$-value and t-value were obtained from the analysis. A p-value of less than 0.05 was considered statistically significant. To compare the outcomes of fluoroscopically guided transforaminal epidural steroid injections in foraminal and paramedian lumbar disc herniation, repeated measures ANOVA was used.
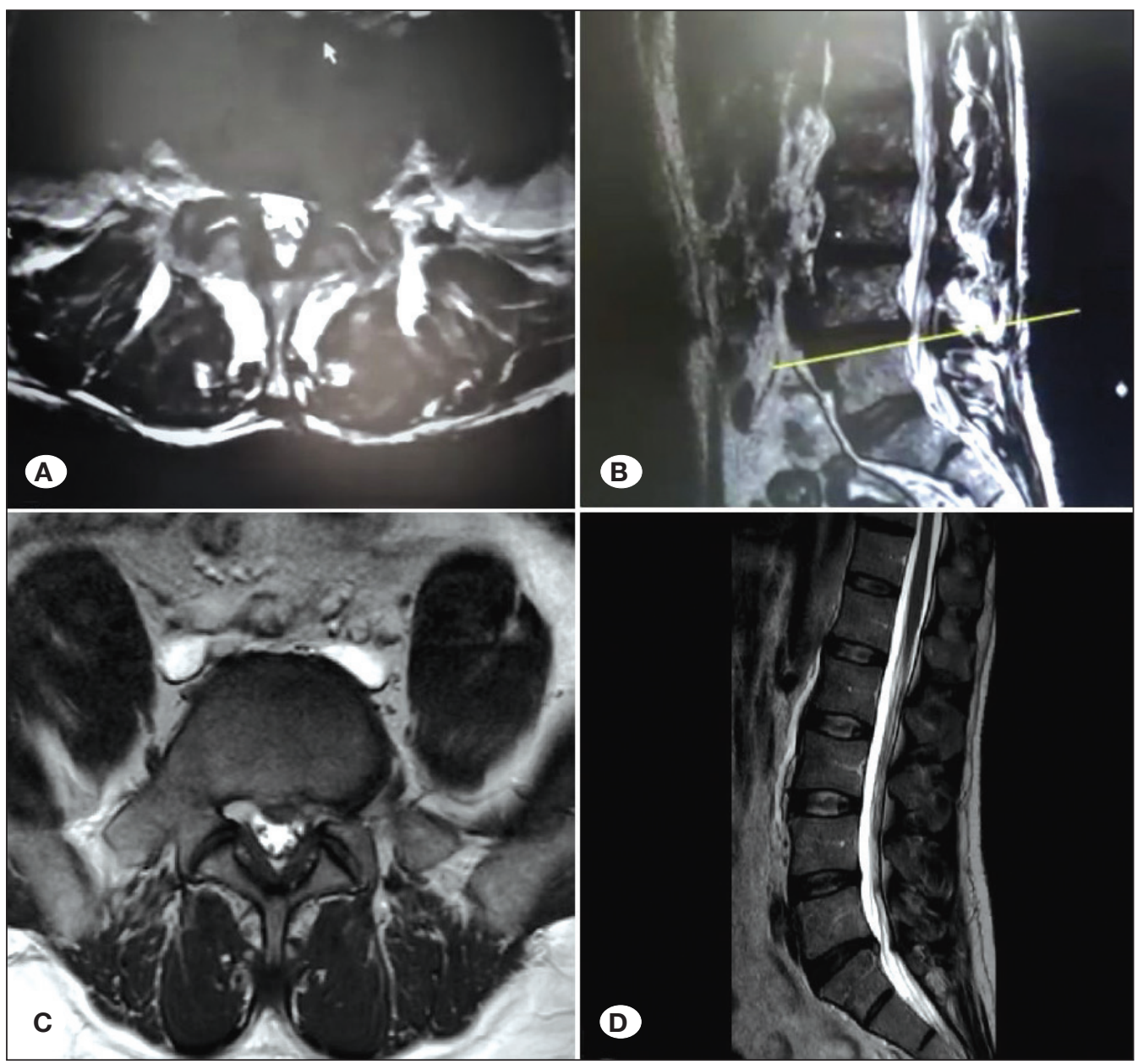

Figure 1: Foraminal lumbar disc herniation; A) Axial, and B) sagittal T2W MRI scans of L4-5 foraminal disc herniation. Paramedian lumbar disc herniation; C) axial, and D) sagittal T2W MRI scans of L5-S1 paramedian disc herniation.
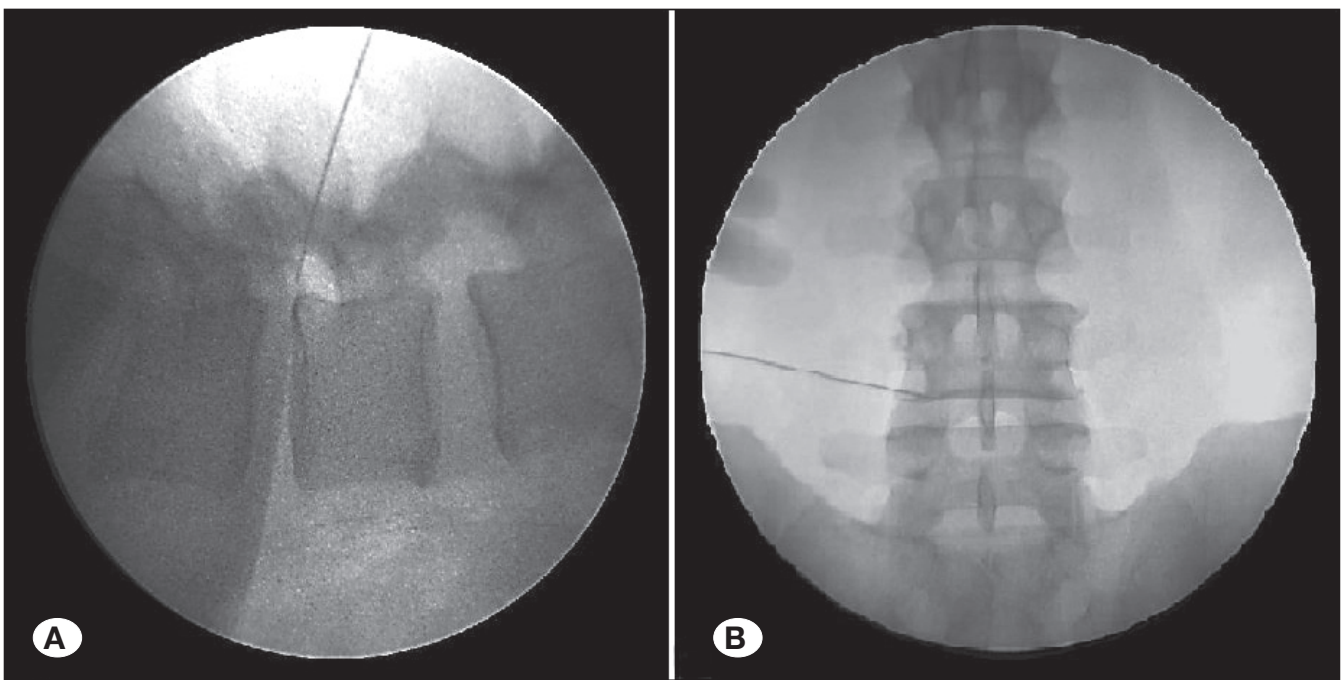

Figure 2: Lumbar

transforaminal epidural steroid injection under C-arm guidance. A) Lateral view, B) anteroposterior view. 


\section{RESULTS}

This study included 1632 patients with a mean age of $53.7 \pm$ 10.94 years (range, 22-87): 625 patients were male and 1007 patients were female (Table I). Approximately 370 patients had foraminal lumbar disc herniation and 1262 had paramedian disc herniation (Table II). All the patients reported radicular pain and were treated with lumbar transforaminal epidural steroid injections.

Patients were evaluated 12 weeks after the procedure. For foraminal lumbar disc herniation, the mean preprocedural and postprocedural VAS scores for radicular pain were $67.11 \pm 4.28$ and $34.78 \pm 3.64$, respectively, and $62.16 \pm 6.65$ and $19.07 \pm$ 4.50 , respectively, for paramedian lumbar disc herniation. The statistical evaluation of the preprocedural and postprocedural VAS score differences between paramedian and foraminal disc herniation shows that transforaminal epidural steroid injections for the former was more effective than for the latter $(p<0.05)$ (Table III).

There were no major complications noted in both groups of patients. In the transforaminal epidural steroid injections group for the foraminal lumbar disc herniation, 16 patients $(4.7 \%)$ had minor complications, namely, infection (1), headache due to intradural injection and CSF fistula (3) and temporary motor deficit (13). In the transforaminal epidural steroid injections group for the paramedian lumbar disc herniation 35 (3.5\%) had minor complications, namely, infection (1), headache due to intradural injection and CSF fistula (7 patients) and temporary motor deficit (27 patients). As regards complications, there was no statistically significant difference between foraminal lumbar disc herniation and paramedian lumbar disc herniation patients ( $p>0.05)$. Approximately nine patients needed surgical intervention for unrelieved pain or increased neurological deficit.

\section{DISCUSSION}

This study primarily aimed to compare the outcomes of fluoroscopically guided transforaminal epidural steroid injections on foraminal lumbar disc herniation and paramedian lumbar disc herniation for the treatment of radicular pain. Other studies on lumbar epidural spinal injections for radicular pain give different results, with efficacy ranging from $0 \%$ to $100 \%$

Table I: Demographic Features of the Patients Who Underwent Transforaminal Epidural Steroid Injection

\begin{tabular}{lcccc}
\hline & $\begin{array}{c}\text { Foraminal lumbar disc } \\
\text { herniation (370 patients) }\end{array}$ & $\begin{array}{c}\text { Paramedian lumbar disc } \\
\text { herniation (1262 patients) }\end{array}$ & $\begin{array}{c}\text { Total } \\
\text { (1632 patients) }\end{array}$ \\
\hline $\begin{array}{l}\text { Gender } \\
\text { (Number of patients) }\end{array}$ & Male & $162(43.8 \%)$ & $463(36.7 \%)$ & $625(38.3 \%)$ \\
\hline Female & $208(56.2 \%)$ & $799(63.3 \%)$ & $1007(61.7 \%)$ \\
Age of the patients & & $\begin{array}{l}53.3( \pm 11.35) \text { years, } \\
\text { (ranged from 22-83) }\end{array}$ & $\begin{array}{c}56.4( \pm 9.87) \text { years, } \\
\text { (ranged from 24-87). }\end{array}$ & $\begin{array}{c}53.7( \pm 10.94) \text { years, } \\
(\text { ranged from 22-87) }\end{array}$ \\
\hline
\end{tabular}

Table II: The Level of Foraminal and Paramedian Disc Herniations Which were Treated by Transforaminal Epidural Steroid Injection

\begin{tabular}{lccc}
\hline & $\begin{array}{c}\text { Foraminal lumbar disc } \\
\text { herniation (370 patients) }\end{array}$ & $\begin{array}{c}\text { Paramedian lumbar disc } \\
\text { herniation (1262 patients) }\end{array}$ & $\begin{array}{c}\text { Total } \\
\text { (1632 patients) }\end{array}$ \\
\hline L1-2 & 3 & 11 & 14 \\
\hline L2-3 & 10 & 27 & 37 \\
\hline L3-4 & 22 & 95 & 117 \\
\hline L4-5 & 187 & 615 & 802 \\
\hline L5-S1 & 148 & 514 & 662 \\
\hline
\end{tabular}

Table III: The Evaluation of the VAS Scores and Number of Complications in Foraminal Lumbar Disc Herniation Patients and Paramedian Lumbar Disc Herniation Patients Who Underwent Single Lumbar Transforaminal Epidural Steroid Injections

\begin{tabular}{|c|c|c|c|c|c|}
\hline & \multicolumn{2}{|c|}{$\begin{array}{l}\text { Foraminal lumbar disc herniation } \\
\text { TFESI patients ( } 370 \text { patients) }\end{array}$} & \multicolumn{2}{|c|}{$\begin{array}{l}\text { Paramedian lumbar disc herniation } \\
\text { TFESI patients (1262 patients) }\end{array}$} & \multirow{2}{*}{ p } \\
\hline & Before TFSEI & After TFSEI & Before TFSEI & After TFSEI & \\
\hline VAS & $67.11 \pm 4.28$ & $34.78 \pm 3.64$ & $62.16 \pm 6.65$ & $19.07 \pm 4.50$ & $p<0.05$ \\
\hline Complication numbers & \multicolumn{2}{|c|}{16 (4.7\%) } & \multicolumn{2}{|c|}{35 (3.5\%) } & $p>0.05$ \\
\hline
\end{tabular}

${ }^{*} p<0.05$, significant. 
and lasting nearly 3 months $(3,25)$. Lechmann et al. reported that patients with disc protrusion and sequestration were more likely to report overall improvement and greater pain reduction at 1 month. Higher pain reduction was also noted in patients with spinal degeneration due to osteophytes, grade 3 foraminal nerve root compression or foraminal / extraforaminal disc herniation location (14). Treatment response was not predicted with $\mathrm{MRI}$ and neurologic assessment findings of patients with chronic low-back-related leg pain (8).

Adequate pain relief was not reported in some lumbar disc herniation patients who had conservative treatment and physical therapy. Less-invasive treatments compared to surgical therapy such as transforaminal epidural steroid injection may be helpful to these patients. Transforaminal epidural steroid injection provides short-term pain relief in patients with single-level lumbar herniated disc and is an effective short-term analgesic that may prevent early surgical intervention (17). An epidural steroid injection can decrease inflammation in the epidural space and pain in the affected nerve root. Steroids may be given epidurally; however, a transforaminal approach increases analgesic efficacy as it increases spread of steroid solution resulting in better contact of the steroid with the ventral side of the root and extruded disc material.

Different studies showed the efficacy of transforaminal epidural steroid injections for the treatment of radicular pain due to lumbar disc herniation $(1,2,4,13,16)$. However, transforaminal epidural steroid injection may not show the same painrelieving effect in other types of lumbar disc herniations due to anatomical and biomechanical reasons. Compared outcomes of fluoroscopically guided transforaminal epidural steroid injections between foraminal lumbar disc herniation and paramedian lumbar disc herniation for the treatment of radicular pain have not yet been reported. This study is the first to compare the outcomes of fluoroscopically guided transforaminal epidural steroid injections of foraminal disc herniation with paramedian disc herniation for the treatment of radicular pain.

During this study, no major complications were noted; however, in the transforaminal epidural steroid injections for the foraminal disc herniation group, 16 patients (4.7\%) had minor complications (including infection, headache, and temporary motor deficit) and 35 (3.5\%) for the paramedian lumbar disc herniation group. This indicates that transforaminal epidural steroid injectionis a safe procedure.

\section{CONCLUSION}

Lumbar disc herniation may cause severe pain that could be relieved with conservative treatment. Surgical intervention is the last treatment of choice in lumbar herniations. Moreover, though with severe pain and neurological deficit, some patients do not want surgical treatment even and some cannot be operated due to old age and are not suitable for anaesthesia. This study showed that transforaminal epidural steroid injection is a safe procedure for appropriate patients with lumbar disc herniation and an effective method to relieve radicular pain and that transforaminal epidural steroid injections were more effective in paramedian lumbar disc herniation than in foraminal lumbar disc herniation in 12-week follow-up period.

\section{- REFERENCES}

1 Adilay U, Guclu B, Deniz L, Kahveci R: Comparison of the effect of single lumbar transforaminal epidural steroid injections for the treatment of L4-5 and L5-S1 paramedian disc herniation. Turk Neurosurg 29(2):279-284, 2019

2. Bhatia A, Flamer D, Shah PS, Cohen SP: Transforaminal epidural steroid injections for treating lumbosacral radicular pain from herniated intervertebral discs: A systematic review and meta-analysis. Anesth Analg 122(3):857-870, 2016

3. Bogduk N, Brazenor G, Christophides N, Cherry D, Fraser $\mathrm{R}$, Jenkins $\mathrm{J}$ : Epidural steroids in the management of low back pain and sciatica of spinal origin: Report of the working party. $2^{\text {nd }}$ ed. Sydney: National Health and Medical Research Council, 1993:102-106

4. Byun JM, Park HS, Woo JH, Kim J: The effects of a forceful transforaminal epidural steroid injection on radicular pain: $A$ preliminary study. Korean J Pain 27(4):334-338, 2014

5. Derby R, Kine G, Saal JA, Reynolds J, Goldthwaite N, White $\mathrm{AH}$, Hsu K, Zucherman J: Response to steroid and duration of radicular pain as predictors of surgical outcome. Spine 17(6):176-183, 1992

6. Devor M, Govrin-Lippman R, Raber P: Corticosteroids suppress ectopic neural discharge originating in experimental neuromas. Pain 22:127-137, 1985

7. Dietrich CL, Smith CE: Epidural granuloma and intracranial hypotension resulting from cervical epidural steroid injection. Anesthesiology 100(2):445-447, 2004

8. Ekedahl H, Jönsson B, Annertz M, Frobell RB: Three week results of transforaminal epidural steroid injection in patients with chronic unilateral low back related leg pain: The relation to MRI findings and clinical features. J Back Musculoskelet Rehabil 29:693-702, 2016

9. Frymoyer JW: Back pain and sciatica. $\mathrm{N}$ Engl $\mathrm{J}$ Med 318(5):291-300, 1988

10. Ghahreman A, Ferch R, Bogduk N: The efficacy of transforaminal injection of steroids for the treatment of lumbar radicular pain. Pain Med 11(8):1149-1168, 2010

11. Gharibo C, Koo C, Chung J, Moroz A: Epidural steroid injections: An update on mechanisms of injury and safety. Techniques in Regional Anesthesia and Pain Management 13(4): 266-271, 2009

12. Johansson A, Hao J, Sjolund B: Local corticosteroid application blocks transmission in normal nociceptive C-fibres. Acta Anaesthesiol Scand 34:335-338, 1990

13. Kawada T: Lumbar transforaminal epidural steroid injection in patients with chronic unilateral radicular pain. Am J Phys Med Rehabil 97(3):e17, 2018

14. Lechmann M, Rosskopf A, Ehrmann C, Sutter R, Pfirrmann CW, Peterson CK: Relationship of specific MRI findings to treatment outcomes in patients receiving transforaminal epidural steroid injections. Skeletal Radiol 45:1677-1685, 2016 
Guclu B. et al: Transforaminal Injection for Lumbar Disc Herniation

15. Manchikanti L: Role of neuraxial steroids in interventional pain management. Pain Physician 5(2):182-199, 2002

16. Manchikanti L, Cash KA, Pampati V, Falco FJ: Transforaminal epidural injections in chronic lumbar disc herniation: A randomized, double-blind, active-control trial. Pain Physician 17(4):489-501, 2014

17. Natarajan S, Krishnamurthy AV, Kalanithi RM, llavarasan MD: Study on the functional outcome of fluoroscopically guided transforaminal epidural steroid injections in patients suffering from lumbar disc herniation. Int J Res Orthop 3(3):607-613, 2017

18. Olmarker K, Størkson R, Berge OG: Pathogenesis of sciatic pain: A study of spontaneous behaviour in rats exposed to experimental disc herniation. Spine 27(12):1312-1317, 2002

19. Parr AT, Diwan S, Abdi S: Lumbar interlaminar epidural injections in managing chronic low back and lower extremity pain: A systematic review. Pain Physician 12(1):163-188, 2009
20. Quraishi NA: Transforaminal injection of corticosteroids for lumbar radiculopathy: Systematic review and meta-analysis. Eur Spine J 21(2):214-219, 2012

21. Saal JS: The role of inflammation in lumbar pain. Spine 20(16):1821-1827, 1995

22. Tachihara H, Sekiguchi M, Kikuchi S, Konno S: Do corticosteroids produce additional benefit in nerve root infiltration for lumbar disc herniation. Spine 33:743-747, 2008

23. Vad VB, Bhat AL, Lutz GE, Cammisa F: Transforaminal epidural steroid injections in lumbosacral radiculopathy: A prospective randomized study. Spine 27(1):11-16, 2002

24. Wewers ME, Lowe NK: A critical review of visual analogue scales in the measurement of clinical phenomena. Res Nurs Health 13:227-236, 1990

25. White AH, Derby R, Wynne G: Epidural injections in the diagnosis and treatment of low back pain. Spine 5:78-86, 1980 